\title{
Determinants of the Performance of Foreign Invested Enterprises in China*
}

\author{
Leonard K. Cheng and Changqi Wu \\ Department of Economics \\ Hong Kong University of Science and Technology \\ Clear Water Bay \\ Kowloon, Hong Kong
}

May 2000

\begin{abstract}
$\underline{\text { Abstract }}$
In this paper, we develop a theoretical framework based on insights from the literature on transaction costs, industrial organization and firm organization and management for the purpose of uncovering the key determinants of the performance of foreign invested enterprises (FIEs) in China. With a data set of 350 foreign invested enterprises collected from a survey in Guangdong and Hainan Provinces, we test hypotheses derived from the theoretical framework. We have found that cash contributed by foreign parent companies had a significantly positive impact on current profitability, but not on subjective performance. There was some evidence that foreign management improved subjective performance. The duration of operation was a consistently positive factor in the success of the FIEs not only in terms of profitability, but also in terms of subjective performance. In addition, FIEs that sold more output to the domestic market performed better, and so did FIEs in industries consistent with China's comparative advantages. FIEs owned by Hong Kong investors did not perform any better than FIEs owned by other foreign investors. Finally, FIEs located in Guangzhou and its vicinity performed better than those located in the SEZs
\end{abstract}

\footnotetext{
"The work described in this paper was substantially supported by a grant from the Research Grants Council of the Hong Kong Special Administrative Region, China (project No. HKUST 484/94H). We thank Professors Paul Beamish, John Child, Yadong Luo, Yigang Pan and David Tse, and the seminar participants at the Hong Kong University of Science and Technology for their comments and suggestions. We are grateful to Professors Chu Xiaoping, Xu Luodan, and Zhu Huihuang for their assistance with the surveys.
} 


\title{
Determinants of the Performance of Foreign Invested Enterprises in China
}

\author{
Leonard K. Cheng and Changqi Wu
}

\section{Introduction}

Multinational corporations (MNCs) are widely regarded as a key driving force in today's global economy. They bring not only capital, but also technology, management, and marketing networks to the host countries. Through their international operations, they help to integrate the world economy and help to improve efficiency. Not unexpectedly, the MNCs' overseas subsidiaries show substantial variations in their performance. An interesting question is what are the key determinants of their performance. In this paper we try to address the question by studying the determinants of the performance of foreign invested enterprises (FIEs) in China. The Chinese experience is important because China has become not only the largest recipient of FDI among all developing economies, but also the second largest recipient in the world in the period from 1993 to 1997 (United Nations, 1999). By the end of 1998, there were over 300,000 foreign invested enterprises (FIE) in China. The cumulative realized FDI reached US\$267.5 billions while the contracted amount stood at $\$ 572.5$ billion. ${ }^{1}$

In the literature there has been a persistent effort to identify factors that account for variations in the performance of FIEs in China from both academic research (Luo, 1998; Pan et. $a l, 1999)$ and business studies (Economic Intelligent Unit, 1997). Thus far the results are mixed. We believe that in order to identify the determinants of the performance of FIEs in China properly, we need to go beyond an analysis of the correlation among the observed variables. A theoretical framework rooted in economic analysis is needed to guide a rigorous analysis of field data. In this study, our analytical framework is based on insights obtained from the recent theoretical development of several related strands of literature and our survey data contain information on the FIEs' external environment, strategic choices and internal organization. Unlike many other studies on FIEs in China, we measure FIEs' performance by both subjective 
and objective indicators, which can be regarded respectively as the long-term prospect and the short-term profitability of the FIEs in China.

Our data were collected from a recent survey of FIEs located primarily in Guangdong Province in south China. ${ }^{2}$ We chose to study FIEs in Guangdong Province because the province was where the open-door policy started. Accounting for well over 30 percent of the total realised and contracted FDI in China, it is the largest recipient of FDI among all Chines provinces, autonomous regions and centrally administered municipalities. Moreover, Guangdong is more developed than most other regions in China in terms of the stage of economic development and the development of market institutions (Vogel, 1989). Lessons learned from Guangdong are relevant to other Chinese regions and possibly other developing countries.

In the next section we develop an analytical framework. A number of testable hypotheses are derived from analytical framework in Section 3. An econometric model is developed in Section 4 and findings are reported in Section 5. In the final section, we offer some concluding remarks and discuss possible extensions.

\section{Analytical Framework}

There are three major strands of literature on firm performance. (a) The industrial organization literature relates firm performance to factors that determine the structure of the market within which the firm operates. (b) The transactions costs literature emphasizes the imperfection of market-based transactions in influencing the allocation of resources, and thus the performance of firms. (c) The theory of organization literature points out the dependence of a firm's performance on its organisational structure, including ownership arrangement and corporate governance.

Since an FIE is a profit-seeking firm operating in the Chinese market, one would expect its performance to depend on the above factors. From the perspective of market structure, the performance of FIEs may depend on the economies of scale and scope, R\&D intensity and

\footnotetext{
${ }^{1}$ The Ministry of Foreign Trade and Economic Cooperation of China (MOFTEC), 1999.
} 
advertising intensity because they may lower the cost of production or create barriers to entry. Other things being equal, FIEs that succeed in entering an imperfectly competitive market with high barriers to entry are expected to perform better, and FIEs in industries that are in China's comparative advantages can compete more successfully in the world market.

Based on transaction costs considerations, Dunning (1988) has proposed an "eclectic" ownership-location-internalization (OLI) model to explain why and when a firm is willing to invest in a foreign country. An FIE faces significantly higher transaction costs than its local competitor due to differences in language, culture, legal system and the level of economic development between the host and home countries (Teece, 1986). To overcome its disadvantages, the FIE must possess sufficiently large advantages in technology and management, etc. More specifically, from the perspectives of transaction costs, cultural and geographical proximity are in favour of the local firms, but the intangible assets and the organisational and managerial capability are in favour of FIEs.

As a determinant of transaction costs, the duration of operation and prior experience in international operations may affect the performance of FIEs (Luo, 1998). The longer is an FIE's operation, the more experience it has accumulated, and thus the better will be its objective performance.

The theory of organization provides an explanation of ownership structure and the allocation of managerial control. Due to transaction costs, complete contracts are impossible. As a partial substitute for a complete contract, the ownership arrangement, by affecting the allocation of residual profits, serves to ensure the various participants' voluntary provision of inputs that are hard to measure. The theory of organization helps to explain why FIEs take the form of joint ventures. This kind of FIE organizational arrangement enables complementary inputs to be brought together in the same organization. Whether a joint venture operates successfully depends on its ownership structure and management arrangement, i.e. the allocation of control rights and benefits among the venture partners. Other things being equal, a joint

\footnotetext{
${ }^{2}$ In our sample of 350 FIEs, 27 are from Hainan, a part ofuangdong Province until 1988, when it became a separate province.
} 
venture will be more successful if the partner with a more critical contribution at the margin has more control rights and enjoys more benefits than others.

Government policy is an important factor of firm performance. In the case of an FIE, government policy may affect its performance through (a) market structure, (b) the relative disadvantages/advantages of the FIE vis-à-vis local firms, and (c) the permitted ownership structure and management arrangements of the FIE. For example, the government may encourage export-oriented FIEs to improve China's current account balance through exports; it may limit foreign ownership to promote joint ventures as a vehicle of technology transfer.

In summary, from a theoretical point of view all of the above factors may have a bearing on the performance of FIEs. However, which factors are most important is mainly an empirical issue.

\section{Data and Hypotheses}

\subsection{Data and Descriptive Statistics}

The data come from a survey of FIEs located in Guangdong Province and Hainan Province conducted between July 1996 and February 1997. Researchers from three universities in Guangdong and a research institute in Hainan were retained to carry out the survey. ${ }^{3}$ To increase the rate of responses, the questionnaires were sent to the FIEs with assistance of the local government departments that were in charge of foreign direct investment. The researchers collected the completed questionnaires from these FIEs. All together, 350 questionnaires were successfully collected.

The questionnaire used in the survey consists of seven sets of questions on the enterprises, covering (1) general background, (2) reasons for investing in China, (3) investment arrangement, (4) inputs of production and markets for outputs, (5) corporate governance, (6) performance, and (7) opinions on government policy. The questionnaire contains of both

\footnotetext{
${ }^{3}$ The universities wereZhongshan University,Guangdong University of Foreign Trade, an 8 hantou University. The institute was the Hainan Research Institute of Economic Development.
} 
qualitative and quantitative questions. Because of the inherent commercial sensitivity involved, several questions are categorical in nature even though the underlying variables themselves are quantitative and continuous, such as assets and profits.

Despite care in the sample selection process to ensure that the included FIEs were as representative as possible, potential biases exist. First, there is a regional bias, because the sample was collected in Guangdong and Hainan Provinces. Second, there is the possibility of a survival bias because only enterprises still operating at the time of survey were selected. Third, there may be a sampling bias because better known enterprises were more likely to be chosen for inclusion than small and obscure ones. Given the above possible biases, our sample may not be representative of the population of all FIEs in China.

Table 1 contains the descriptive statistics of FIEs in our sample. Among the entire sample of 350 FIEs, 201 were equity joint ventures (EJVs), 62 were contractual joint ventures (CJVs) and the remaining 87 ventures were wholly foreign-owned enterprises (WFOEs). The majority of foreign investors was from Hong Kong, to be followed by investors from the US. The distribution of these FIEs' time of establishment in the period of 1980-1996 was similar to that of the population of FIEs in China.

\subsection{Performance Measures}

Since firms in a capitalist system are set up to make profits, the most natural measure of a firm's performance would be its profitability. As an ongoing concern, a firm's profitability should be its long-term profitability. However, this information is impossible to obtain. As a result, proxies of long-term profitability such as cost, market share, and growth rate are used to supplement current or past profitability. In some studies, the survival of enterprises (Stigler, 1958; Weiss, 1964; Franko, 1971; Pan and Chi, 1999), their duration (Harrigan, 1985; Kogut, 1989) and the stability of their ownership (Gomes-Casseres, 1989) also serve as indicators of performance.

In this study, profitability defined as total profits in 1995 divided by total sales in the same year is used as the primary objective performance measure. Because of the sensitivity of 
the operating profits, we only asked the surveyed firms to choose one among six categories of profitability, ranging from over 15 percent to heavy losses. ${ }^{4}$ Thus, the information on FIEs' objective performance obtained from the survey was a categorical variable. ${ }^{5}$

The measurement of the objective performance of FIEs is often plagued by the lack of information on parent-subsidiary relationship and non-comparability of data across enterprises. Parent companies may generate returns from their foreign subsidiaries not only from the subsidiaries' profits, but also from supply contracts, management fees, technology licensing fees, royalty, etc. Moreover, when a firm engages in a new technological field such as internet and new market like China, the short-term accounting and financial measures are often not capable of capturing their long-term profitability.

In reaction to these and other difficulties of measuring objective performance, in recent years a number of studies have employed subjective indicators such as managers' perception of their firms' performance. The subjective indicators are considered better indicators than the objective indicators in that the former may have captured the long-term and non-financial aspects of the enterprises' performance. For example, Killing (1983) and Beamish (1984) propose to use a parent's satisfaction with a joint venture's performance as the venture's performance indicator. Geringer and Hebert (1991) study the relationship between the objective and subjective performance measures of international joint ventures along several dimensions. They find a positive correlation between the two measures, but the correlation coefficients vary depending on indicators used and on the joint venture partners.

Following the lead of this literature, we have included in our questionnaire a set of questions on the subjective performance of the FIEs. We believe that the subjective performance is more informative about the FIEs' future performance than profitability measured in the year

\footnotetext{
${ }^{4}$ For the profitable FIEs, they chose one of the four categories of profitability: above 15 percent, between 8 percent and 15 percent, between 3 percent and 8 percent, and below 3 percent. For the loss-making FIEs, they chose between minor and heavy losses.

${ }^{5}$ In addition to the profits/sales ratio obtained directly from the survey, we have constructed a data using the total profits and the total assets. The exercise does not produce any unexpected and surprising results. Because the data construction may introduce additional biases due to the categorical nature of the variables used, we do not report the result here.
} 
before the survey was conducted. In the case of joint ventures, the performance is that of the FIEs, not the venture's partners or their parent companies. ${ }^{6}$

In the survey, the managers of FIEs were asked to choose one of four categories (excellent, good, satisfactory, and unsatisfactory) to describe the overall performance of their respective enterprises. We also asked each enterprise to indicate which of four factors (profitability, marketing networks, technological upgrading, and cost reduction) was given the most weight in arriving at their subjective assessment of the enterprise's performance. The responses show that cost reduction was considered the most important criterion in determining the enterprises' subjective performance. The summary statistics of the subjective and objective performance indicators are given in Table 2.

\subsection{Explanatory Variables of FIE Performance}

Based on the discussion of an appropriate analytical framework in Section 2, we have identified four factors that are most likely to affect the performance of FIEs. These factors are (1) organization and management control, (2) transaction costs, (3) market structure, and (4) government policies. The potential determinants of FIE performance are therefore grouped into these four clusters of variables.

\section{(1) Organization and Management Control}

Complementarity of skills and assets is often considered one of the most important motivations for firms to form a joint venture. The actual commitment of resources at the time of a joint venture's establishment has a significant impact on the performance of the venture. For instance, Child and Yan (1999) have found that the performance of joint ventures in China depends on the amount of capital employed and the parents' supply of key inputs. In general, the inputs committed to the venture may take the form of cash, equipment, technology, management skills, and land. But if the venture is going to succeed, the parents' contribution should be

\footnotetext{
${ }^{6}$ In the studies ofGeringer andHeberts (1991) and Child andYan (1999), the researchers interviewed both local and expatriate managers in joint ventures to formulate the subjective performance measures. The sample size used in this type of study usually is small because of resource constraints. However, Anderson (1990) argues that the joint ventures should be evaluated primarily as stand-alone entities seeking to maximize their own performance, not the parents' objectives.
} 
compatible with the parents' comparative advantages. Because intangible assets are the main reason for foreign firms to invest directly in a foreign country, we postulate the following hypothesis

Hypothesis 1: FIEs perform better if the foreign parents contribute relatively more in management skills or technology than Chinese parents.

While the nature of resources committed by the venture partners is important, the effective utilisation of these resources in the joint venture's operation would be even more important. If we accept the assumption that foreign management is more effective than Chinese management, then the venture's performance depends on the managerial role played by the foreign partner.

Hypothesis 2: The FIE's performance is better if the foreign partner has greater control over the enterprise.

One can use several alternative indicators to measure the extent of control by the foreign partners. For example, (1) equity share of foreign partners in the venture, (2) representation of foreign investors on the board of directors, (3) percentage of foreign managers, and (4) management by foreign partners (a dummy variable).

\section{(2) Transaction Costs}

According to Teece (1986), transaction costs are one of most important determinants of the performance of international operations. The magnitude of transaction costs depends on location, cultural proximity between the host country and the foreign investors' home countries. By focusing on FIEs in Guangdong, the impact of location differences in the host economy was alleviated, but investors from Chinese societies (Hong Kong, Macau, Taiwan, and to a lesser degree Singapore) may enjoy an advantage based on their cultural and geographical proximity to their host economy. That is to say, the transaction costs may vary according to the origin of foreign investors. 
Hypothesis 3: FIEs owned by investors from Asian economies, particularly those from the Chinese societies (Hong Kong, Macau, and Taiwan) will enjoy better performance.

Another determinant of the magnitude of transaction costs is the experience of operating in China. We use the number of years of operation since the venture was established to capture the effect of experiences in China.

Hypothesis 4: The longer the FIEs have operated in China, the better is their performance.

The operation of multiple enterprises in China by the same foreign parent may lower the operation costs as well as transaction costs. In this way, the experience learned by one venture benefits other ventures of the same parent company. Nevertheless, depending on the nature of experience of the operations in China, the experience learned from one FIE may or may not be relevant (Child and Yan, 1999).

Hypothesis 5: An FIE's performance depends positively on the number of FIEs in China owned by its foreign parent.

If the relationship between experience and objective performance is already correctly anticipated and taken into account, then experience may not affect the subjective measures of performance. Thus, the relationship between duration of operation and the FIEs' subjective performance may not be as strong as that between duration and objective performance.

\section{(3) Market Structure}

The industrial organization literature emphasizes the relationship between market structure and economic performance. In the case of FIEs, the barriers to entry may not only include technical barriers to entry such as economy of scale, but also the institutional barriers such as restriction on FIEs' products in China's domestic market. 
It is widely believed that the most important barriers to entry are the restrictive rules of the government, explicit or implicit, to protect China's domestic industries. Those firms that are allowed to sell in China's domestic market may benefit from local market's protection from international competition. In contrast, FIEs exporting their products instead must face international competition, and the performance depends on whether they operate in industries that are in China's comparative advantages.

Hypothesis 6: An FIE with a larger share of export sales will have poorer performance.

Nevertheless, since the export-oriented firms typically produce labour-intensive goods that are in China's comparative advantages and the Chinese government has adopted policies to encourage FIEs to export their products, the relationship between FIEs' performance and exports may be ambiguous after all.

Hypothesis 7: An FIE's performance depends on whether its industry is in China's comparative advantages.

Given China's endowments, its comparative advantage, lie in labor intensive industries and its comparative disadvantages lie in technology-intensive and land-intensive industries.

\section{(4) Government Policies}

The Chinese government has adopted a series of policies to attract FDI and the establishment of SEZs was a key policy instrument. FIEs located in the SEZs operated in a more market-oriented environment and enjoyed preferential treatment in profit taxes and tariffs. ${ }^{7}$ Shenzhen, Zhuhai, Shantou were established in Guangdong in the late seventies and early eighties. Hainan became an SEZ in 1988 when it split from Guandong to become a province of its own. From these facts, we postulate

Hypothesis 8: FIEs located in SEZs perform better than FIEs located outside SEZs.

\footnotetext{
${ }^{7}$ Because of the experimental nature o\$EZs, many preferential policies initially introduced fiEZs subsequently spread to other coastal cities (Cheng, 1995).
} 


\section{The Econometric Model}

Because the performance indicators are categorical variables, we adopt the ordered probit regression model to conduct our empirical analysis. The underlying model is

$$
Y_{i}=\beta \quad X_{i}+\varepsilon_{i}
$$

where $Y_{i}$ is the continuous dependent variable measuring the performance of FIE ${ }_{i}$. $Y$ may be the subjective or objective performance measure. $X_{i}$ captures the key characteristics of the firm. The value of $Y_{i}$ is not directly observable, but we know which category it falls into. From the ordered probit regression model, the probability that $Y_{i}$ falls in one of categories is given as follows,

$$
\begin{aligned}
& P_{k}\left(\varepsilon<\beta X_{i}\right)=F\left(\beta X_{i}\right) \\
& P_{k-1}\left(\beta X_{i}<\varepsilon<\beta X_{i}+\alpha_{1}\right)=F\left(\beta X_{i}+\alpha_{1}\right)-F\left(\beta X_{i}\right) \\
& \cdot \\
& \cdot \\
& P_{1}\left(\varepsilon>\beta X_{i}+\alpha_{1}+\alpha_{2}+\cdots+\alpha_{k-2}\right)=1-F\left(\beta X_{i}+\alpha_{1}+\alpha_{2}+\cdots+\alpha_{k-2}\right)
\end{aligned}
$$

where $\mathrm{F}$ is the cumulative logistic distribution function. Because $\mathrm{Y}$ is underlying unobserved continuous dependent variable, we define $Z_{i j}=1$ if $Y_{i}$ falls in category $j$, and $Z_{i j}=0$ otherwise. The explanatory variable $\mathrm{X}_{\mathrm{i}}$ represents the factors that influence the performance of $\mathrm{FIE}_{i}$, i.e., each of the four groups of determinants (organization/management; transaction costs; market structure; government policies) is represented by an element of $X_{i}$

By spelling out the exact variables to capture the four groups of determinants of FIE performance as discussed in Section 2, we obtain the following core regression model.

$$
Y_{i}=\sum_{j=1}^{27} \beta_{j} X_{j i}+\varepsilon_{i}
$$


where the definition of the explanatory variables is given in Table $3 \mathrm{a}$ and $\varepsilon_{\mathrm{i}}$ captures the random factors that influence the performance of the FIEs. When implementing the empirical investigation, same alternative variables are used to test the sensitivity of the model. The statistical properties of the non-dummy explanatory variables are given in Table $3 \mathrm{~b}$.

\section{Empirical Findings}

To implement our empirical investigation, we use the statistical functions and probit regression program provided by the software package, Stata 6.0. The results of statistical analyses are reported in this section. In the first part, we report some correlation relationships among the key variables. Regression results of the basic probit models are reported in subsection 5.2. In addition, we also report the results of additional models for the purpose of testing the robustness of the basic models.

\subsection{Statistical correlation relations}

The correlation coefficients between the subjective and objective performance measures and between the performance measures and explanatory variables are summarised in Table 4. Several interesting observations can be made.

\section{(a) Correlation between the objective and the subjective performance measures}

Consistent with Geringer and Hebert's study (1991), the correlation coefficient between the objective and subjective performance indicators is 0.49 , as is shown in Table 4.a. That is to say, the subjective and objective performance measures are positively but weakly correlated. Due to the categorical nature of these two variables, we have also computed the Spearman rank correlation coefficient between the variables. The coefficient is 1.0013 , which means we can reject the null hypothesis of no relationship between these two series of variables at the 15 percent significance level. These two weak positive correlative relationships suggest that the subjective and objective performance indicators may depend on different sets of factors. 
(b) Correlation among export intensity, import of equipment and technology from the foreign parent companies

As the correlation coefficients in Table 4.b indicate, these three variables are positively correlated. One possible explanation is that the export processing FIEs relocate their equipment and technology from their own economies to China to take advantage of the cheap labour and land in building their production base for exports to the world market. The correlation between foreign equity share and the equipment purchase from the foreign parent companies is much stronger than the relationship between foreign equity share and foreign equipment in general, indicating that foreign investors prefer acquiring equipment from their parent companies instead of from unrelated foreign suppliers.

\subsection{Results of Regression Analysis}

Regression results of the ordered probit models for objective and subjective performance measures are summarised in Table 5 and 6 respectively. The results show that objective performance of FIEs depends on the foreign investors' cash contribution. While duration of FIEs'

formation has a significantly positive impact on both measures of performance, the effect of multiple ventures on the performance was much weaker, especially in the case of profitability. Surprisingly, location in the SEZs had a negative impact on performance. Detailed explanation and interpretation of the results are provided as follows.

\section{(a) Organization and management}

When FIEs in our sample were asked to provide reasons to choose joint ventures as the mode of entry, the most frequently cited reason was that a joint venture could utilise their complementary assets. An empirical question is what kind of assets from foreign partners was most effective in improving performance of joint ventures. Child and Yan (1999) report that provision of capital by foreign partners was positively correlated with the performance FIEs but gave no specifics on the actual form of capital in their study. 
Table 5 shows the impact of various forms of capital input from foreign investors. From that table, we see that FIEs without cash input from foreign parents had lower profitability, the objective performance measure. Contrary to Child and Yan's (1999) findings, the negative coefficients for "no cash and technology" suggest that input from the foreign parents in the form of equipment alone had a negative impact on the FIEs' profitability, but the effect was not statistically significant except in model $1 .{ }^{8}$ In contrast, in Table 6, the coefficients of "no cash" were insignificant, but surprisingly some of the coefficients associated with "no cash and equipment" (i.e. technology was the only input provided by foreign partners) were significantly negative suggesting either cash or equipment or both contributed to subjective performance.

Thus, the results on the form of investment by foreign partners are mixed. They seem to suggest that cash input from foreign parents could alleviate the liquidity constraints of the FIEs in the short run, thus facilitating the operations and increasing profitability. Surprisingly, we have failed to discover any positive impact of the foreign partners' technology input on both the objective and subjective performance measures.

The equity share determines how an FIE's profits are divided among the partner firms, and thus serve to induce efficient supply of hard-to-verify inputs. The effective management of the venture, however, may also depend on the venture's governance structure. A recent study shows that the foreign equity ownership improves firms' performance only under the condition of majority ownership by foreign investors (Chhibber and Maumdar, 1999). To highlight the role of the governance structure, we adopted three indicators, namely the percentage of the foreign directors of the board, the percentage of foreign mangers, and the dummy variable of enterprise's management by foreign partners third party or foreign management firms. Because of the close correlation among the above four variables we use them one at a time, thus generating the four models.

\footnotetext{
${ }^{8}$ The difference between the coefficients of "no equipment and technology" and those for "no technology" suggests that equipment input from the foreign parents hurts profitability, but the difference between the coefficients of "no cash and equipment" and those for "no cash" suggests that equipment helps profitability. Nevertheless, the differences are insignificant in both cases.
} 
In the case of subjective performance, the higher the equity share of foreign companies, the better the FIE's performance. In light of Chhibber and Majumdar (1999) we replaced the continuous variable of foreign equity share by a dummy variable of majority foreign equity share, but the results were largely intact. This result is consistent with Hypothesis 2. The coefficient for "foreign managers" had the same sign but was slightly less significant. In terms of objective performance, none of the four variables shows any significant impact.

That is to say, our results support Hypothesis 2 in the case of subjective performance but not in the case of profitability. They are consistent with anecdotal observation that the expensive expatriate managers may push up the cost of operations in the short term, but their managerial skills are expected to contribute to longer-term profitability.

\section{(b) Transaction costs}

Although cultural proximity and geographical distances are factors that influence transaction costs, the coefficients of the country of origin dummies indicate that FIEs from Hong Kong did not perform better than FIEs from other economies. This outcome fails to support Hypothesis 3. A similar result has been reported in Kao (1996) who has found that enterprises from the US and Japan performed better than those from Hong Kong/Macau, while the latter performed better than enterprises from Taiwan.

The disproportionally large share of FDI from Hong Kong seems to imply that Hong Kong enterprises perform better than enterprises from other economies. Our finding is also inconsistent with Hong Kong's dominant role as a supplier of FDI to China (Schroath et. al, 1993), and contradicts the commonly held belief that geographical proximity and cultural similarity between Guangdong and Hong Kong give Hong Kong investors substantial competitive advantages.

An unresolved paradox is: if Hong Kong based companies do not have competitive advantages, why was there such large investment flows for so many years? Notice that the dummy variable "Hong Kong" was positively though weakly correlated with export intensity and 
contribution of equipment by the foreign parents. Could the lackluster performance be the result of transfer pricing via exports? Further work would be necessary to provide an answer.

The coefficients of the natural log of duration of operation are positive and statistically significant in all cases. ${ }^{9}$ That means the longer a FIE has been in operation, the better is its performance based on both subjective and objective measures. This result supports Hypothesis 4. It is also consistent with what has been reported in the literature (Luo, 1998; Pan, Li and Tse, 1999).

Using a data set of 162 FIEs operating in the light industry sector in Jiangsu Province from 1982-1990, Luo (1998) examines the effect of timing of investment on FIE's performance, measured by returns on investment (ROI), sales growth, assets turnover, and operational risk reduction. The timing of entry may influence the performance of FIEs in three ways: first-mover advantage has a positive effect, but risks associated with new products have a negative effect, and the under-development of market institutions also lowers the efficiency of operation. He has found that early entrants performed better than late comers in terms of local market expansion and asset turnover, whereas late comers performed better than early entrants in areas of risk reduction and accounting returns on investment during the initial three-year period of the operation.

Using data from the 1995 industrial census of China, Pan, Li and Tse (1999) study the performance of FIEs measured by market share as well as returns on assets and report that firm performance was affected by the order of market entry and by the mode of entry. They have found that, consistent with the hypothesis of first-mover advantage, the early entrants performed better than the latecomers in both measures. With respect to the modes of entry, they report that the WFOEs had the highest market shares, followed by EJVs and CJVs while the profitability of EJVs was the highest, followed by CJVs and WFOEs.

Our finding shows that the experience of FIEs operating in China not only leads to higher current profits, but also creates a competitive position that improves the long-term prospect. Our 
results about multiple ventures, however, are mixed. It has a positive and statistically significant impact on the subjective performance, in some models, but the impact is insignificant in the models of objective performance. That is, Hypothesis 5 is only partially supported.

\section{(c) Market structure}

Consistent with Kao's finding that an FIE's sales in China's domestic market was positively correlated with its profitability, we have found that FIEs that have higher export ratios are more likely to have lower profitability than those who have more domestic sales. However, the coefficients are not statistically significant. ${ }^{10}$ Thus, Hypothesis 6 is not supported by our result.

The coefficients of industry dummy variables show that the electronics industry was the only industry that consistently performed better than the benchmark garment industry in terms of objective performance. The agricultural/food products, glass/ceramic ware, and electrical equipment/product industries performed significantly worse than the benchmark industry in terms of subjective performance.

These results are similar to Kao (1996) who shows that FIEs in basic metal, plastics and leather products were less profitable than those in electrical and electronics. The former industries are clearly more capital intensive than the latter. Our results differ from Kao in the sense that we separate the electrical equipment and products from electronics products and find that the electronics industry performed better than, but the electrical equipment and products industry and the agricultural/food product and glass/ceramic ware industries performed worse than the benchmark garment industry.

Our findings on the relationship between performance and industries support Hypothesis 7 and are consistent with the prediction of Heckscher-Ohlin theory of international trade because

\footnotetext{
${ }^{9}$ The coefficients of "n (duration of operation)" were more significant than those for "duration of operation" but qualitatively similar. This is consistent with the intuition that useful experience increases less than proportional to the time of operation.

${ }^{10}$ Kao's finding was lased on a survey conducted in 1993 on the operations of 1066 FIEs in China in 1992. He also reported that the domestic sales and capacity utilization of FIEs were positively correlated with their profitability.
} 
China is abundant in labour but scarce in capital and land. The labor-intensive industries like electronics assembly utilize China's comparative advantages and tend to perform better than the capital-intensive industries like the electricity equipment and products and land-intensive industries such as agricultural/food industries. ${ }^{11}$

\section{(d) Government policy}

We introduce a dummy variable to control for the effect of SEZs on the performance of FIEs. The significantly negative signs of the coefficients of the SEZ dummy rejects Hypothesis 8. The result is totally unexpected in light of the preferential treatment given to FIEs located in SEZs. It should be pointed out that in our sample FIEs not located in SEZs were located in cities in the Pearl River Delta, including Guangzhou, the capital city of Guangdong Province. A possible explanation is that these cities were not only cheaper than the SEZs in land and labor, but also more aggressive in accommodating the demand of foreign investors. This finding is reminiscent of Pan and Chi's (1999) finding that FIEs located in Beijing, Shanghai and Tianjin performed better than those located in SEZ in their sample. Among the four SEZs, we have found that FIEs in Shenzhen and Zhuhai performed better than FIEs located Shantou and Hainan.

\subsection{Other Potential Factors of FIE Performance}

\section{(a) Relationship with the government}

In the context of China's business environment, it is widely believed that connection (guanxi) is an important factor of business success in China. The Chinese parent company's affiliation to the government is often considered an indicator of potential resources because the relations can be exploited to enhance the JV's competitive advantages. The Chinese parent

\footnotetext{
${ }^{11}$ In lieu of industry dummies, we have used the average profitability of China's enterprises by industry (an indicator of degree of market competition) in the sample period as explanatory variables for the performance of FIEs, but the coefficients are not statistically signi ficant. Howeveeuo (1999) has found that industry-wide sales growth and output growth can be used to predict the performance bfEs in the EasternChiniese province of Jiangsu.
} 
company may be a state-owned enterprise (SOE), collectively owned enterprise, township and village enterprise, private enterprise and enterprise with joint stock ownership.

The close relationship between an SOE and the government may translate into the supply of key inputs such as land. However, Beamish (1993) argues that in the case of a government partner the foreign partner cannot assume the Chinese partner's profit motivation, speed of decision making, desire for efficiency, etc. are similar to those of joint ventures formed between two private sector organizations.

In the statistical analysis, we added an SOE dummy variable to test for the effect of Chinese parent companies. Although the sign of coefficient for the SOE dummy was positive in the models, none was statistically significant. Th hypothesis that the closer the Chinese parent companies to the government, the better is the FIEs' performance is not supported. It seems that the influence of government affiliation on both the subjective and objective performance measures of FIEs may have been exaggerated.

\section{(b) Size of investment}

The amount of investment is a measure of the scale of capital input, a factor potentially contributing to performance of FIEs. From Table 3, we can see that the average size of investment of FIEs in our sample was $\$ 9.4$ million with the maximum of over $\$ 400$ million and the minimum of only $\$ 18,000$. When the invested capital was included as an additional variable in the basic probit models, its coefficient in the objective performance models was negative and statistically significant; the coefficient in subjective performance modes was also negative but not statistically significant.

One possible explanation is that FIEs in capital intensive industries are against China's comparative advantage. In addition, it typically takes a longer time for a larger investment project to pay off than a smaller one. That can explain why the statistical significance of negative effect was for the objective performance indicator, but not for the subjective performance indicator. These results are consistent with the common advice that FIEs in China should have a longer planning horizon. 


\section{(c) Modes of FDI}

FIEs in China typically take one of three forms: EJV, CJV, and WFOE. These three modes of FDIs represent three different kinds of entry strategies and may cause the performance of FIEs to vary. While the difference between WFOEs and EJVs is already captured by the percentage of equity shares owned by their foreign parents, CJVs are different because they represent contractual arrangements in which the benefits and obligations of foreign investors are explicitly spelt out. When a dummy variable of CJV is added to control for the impact of the contractual arrangement on performance, the coefficient is negative in all four models of objective performance and is statistically significant at the $10 \%$ level except for model 3 in Table 5. This result is consistent with a general observation of the diminishing importance of CJVs as a form of FDI in China in recent years. The coefficient, however, is not statistically significant in all the subjective performance models.

\section{Concluding Remarks}

In this paper we have developed a theoretical framework for the performance of FIEs in China, derived hypotheses about the key determinants of FIE performance and tested the hypotheses with data obtained from a survey of FIEs in Guangdong and Hainan Provinces in 1996/97. The theoretical framework is based on insights from the literature on transaction costs, industrial organization, and firm organization and management. Both the objective performance indicator (profitability) and the subjective performance indicator (evaluation by managers) are used as the dependent variables. The former provides information on the current state of FIE operation while the latter captures the long-term prospects of the firms. Given the categorical nature of the dependent variables, we have adopted the ordered probit regression model to analyze the data.

On the question of assets contribution to FIEs, we have found that cash contribution by foreign parent companies had a significant positive impact on current profitability, but not on 
subjective performance. In additional, foreign management as proxied by the shares of foreign equity and foreign managers had a significant effect on subjective performance.

As a parameter of transaction costs, the duration of operation was a consistently positive significant factor in the success of the FIEs, not only in terms of profitability, but also in terms of subjective performance. That is to say, the early entrants tended to outperform the latecomers. In contrast, experience as measured by the number of FIEs owned by the foreign parent companies had a significant contribution to subjective performance, but negligible contribution to objective performance. Whether or not foreign investors were from Hong Kong had no significant effect at all.

From the perspective of market structure, we have found that FIEs that exported more performed worse than other FIEs that sold more goods to the domestic market. The differential intensity of competition between domestic and international markets may account for this finding. In addition, FIEs in industries that were in China's comparative advantages tended to perform better than those in China's comparative disadvantages.

On the effect of government policy on performance, we have found a surprising result, namely, FIEs located in the special economic zones performed significantly worse than those located outside the zones in both subjective and objective measures. That suggests that by 1995/96, in comparison with Guangzhou and its vicinity, the SEZs had lost their attractiveness to the FIEs. 


\section{Reference}

Anderson, Eric and Hubert Gatingnon, 1986, Modes of Foreign Entry: Transaction Economics and Propositions, Journal of International Business Studies, 17, 1-26.

Anderson, Eric, 1990, Two Firms, One Frontier: On Assessing Joint Venture Performance, Sloan Management Review, Winter, 19-30.

Beamish, Paul.W. 1984, Joint Venture Performance in Developing Countries, unpublished Ph.D. dissertation, University of Western Ontario, London.

-------, 1993, The Characteristics of Joint Ventures in the People's Republic of China, Journal of International Marketing, 1(2).

Caves, Richard, E., 1996, Multinational Enterprises and Economic Analysis, $2^{\text {nd }}$ edition, Cambridge University Press.

Cheng Leonard K., 1995, Foreign Direct Investment in China, Paris: OECD.

Cheng, Leonard K. and Yunkong Kwan, 1999, What are the Determinants of the Location of Foreign Direct Investment? The Chinese Experience, Journal of International Economics, forthcoming.

Chhibber, Pradeep K and Sumit K. Majumdar, 1999, Foreign Ownership and Profitability:

Property Rights, Control, and the Performance of Firms in Indian Industry, Journal of Law and Economics, 42, 209-238.

Child, John and Yanni Yan, 1999, Predicting the Performance of International Joint Ventures: An Investigation in China, Chinese Management Centre, The University of Hong Kong, Working Paper.

The Economist Intelligent Agent, 1997, The Multinational Companies in China, Winners and Losers.

Franko, Lawrence, 1971, Joint Venture Survival in Multinational Corporations, New York: Praeger Publishers.

Geringer, J. Michael and Louis Hebert, 1991, Measuring Performance of International Joint Ventures, Journal of International Business Studies, (2), 249-263

Gomes-Casseres, Benjamin, 1989, Ownership Structures of Foreign Subsidiaries: Theory and Evidence, Journal of Economic Behavior \& Organization,11 (1) 1-25.

---, 1990, Firm Ownership Preferences And Host Government Restrictions, Journal of International Business Studies; First Quarter, 1-22.

Harrigan, Kathryn, 1985, Strategies of Joint Ventures, Lexington: MA: D.C. Heath. 
Kao, Chang, 1996, The Determinants of Profitability of Foreign Invested Enterprises in Mainland China, Conference Proceedings, 1996 Taiwan Economic Association Annual Conference.

Killing, J. Peter, 1983, Strategies for Joint Venture Success, New York: Praeger.

Kogut, Bruce, 1989, The Stability of Joint Ventures: Reciprocity and competitive Rivalry, Journal of Industrial Economics, 38, 183-198

Luo, Yadong, 1995, Business Strategy, Market Structure, and Performance of International Joint Ventures: The Case of Joint Ventures in China, Management International Review, 35, 241264.

----, 1998, Timing of Investment and International Expansion Performance in China, Journal of International Business Studies, 29(2), 391-407.

----, 1999, The Structure-Performance Relationship in a Transitional Economy: An Empirical Study of Multinational Alliances in China, Journal of Business Research, 46(1), 15-30.

Pan, Yigang, Shaomin Li and David K. Tse. 1999, The Impact of Order and Mode of Market Entry on Profitability and Market Share, Journal of International Business Studies, 30(1), 81104.

Pan, Yigang and S.K. Chi, 1999, Financial Performance and Survival of Multinational Corporations in China, Strategic Management Journal, 20(4) 359-374.

Schroath, Frederick W., Michael Y. Hu and Haiyang Chen, 1993, Country-of -Origin Effect of Foreign Investments in the People's Republic of China, Journal of International Business Studies, second quarter, 277-290.

Stigler, George, 1958, The Economies of Scale, Journal of Law and Economics, 1, 54-71. United Nations, 1999, World Investment Report, New York: UNCTAC.

Vogel, Ezra F. 1989, One Step Ahead in China: Guangdong under Reform, Cambridge, MA: Harvard university Press.

Weiss, Leonard, 1964, Survival Technique and the Extent of Sub-Optimal Capacity, Journal of Political Economy, 72, 246-261. 
Table 1. Descriptive Statistics

a. Origin of Foreign Investors

\begin{tabular}{l|ccc|c}
\multicolumn{5}{c}{ Types of FIEs } \\
\hline Country of origin & EJV & CJV & WFOE & Total \\
\hline Australia & 1 & 0 & 0 & 1 \\
Canada & 1 & 1 & 0 & 2 \\
France & 1 & 0 & 0 & 1 \\
Germany & 1 & 0 & 1 & 2 \\
Hong Kong & 133 & 47 & 49 & 229 \\
Japan & 11 & 2 & 3 & 16 \\
Korea & 1 & 0 & 0 & 1 \\
Macau & 4 & 0 & 1 & 5 \\
Malaysia & 3 & 1 & 0 & 4 \\
Netherlands & 1 & 0 & 0 & 1 \\
Singapore & 7 & 1 & 3 & 11 \\
Switzerland & 1 & 0 & 0 & 1 \\
Taiwan & 5 & 1 & 11 & 17 \\
Thailand & 3 & 2 & 1 & 6 \\
UK & 3 & 0 & 1 & 4 \\
US & 15 & 3 & 4 & 22 \\
Info not available & 10 & 4 & 13 & 27 \\
\hline Total & 201 & 62 & 87 & 350 \\
\hline
\end{tabular}

b. Year of FIEs' First Registration

\begin{tabular}{c|cc|rc}
\hline Year & \multicolumn{1}{l}{ Sample } & Percentage & Nation-wide & Percentage \\
\hline $1979-82$ & 2 & 0.6 & 922 & 0.3 \\
1983 & 2 & 0.6 & 470 & 0.2 \\
1984 & 5 & 1.5 & 1,856 & 0.7 \\
1985 & 9 & 2.6 & 3,073 & 1.1 \\
1986 & 3 & 0.9 & 1,498 & 0.5 \\
1987 & 10 & 2.9 & 2,233 & 0.8 \\
1988 & 13 & 3.8 & 5,945 & 2.1 \\
1989 & 18 & 5.3 & 5,779 & 2.0 \\
1990 & 42 & 12.4 & 7,273 & 2.6 \\
1991 & 49 & 14.4 & 12,978 & 4.6 \\
1992 & 48 & 14.1 & 48,764 & 17.2 \\
1993 & 73 & 21.5 & 83,437 & 29.4 \\
1994 & 40 & 11.8 & 47,549 & 16.8 \\
1995 & 15 & 4.4 & 37,011 & 13.1 \\
1996 & 11 & 3.2 & 24,556 & 8.7 \\
Info not available & 10 & - & - & \\
\hline Total & 350 & 100.0 & 283,344 & 100.0 \\
\hline
\end{tabular}


c. Location of FIEs

Types of FIEs

\begin{tabular}{l|ccc|c}
\hline Regions & EJV & CJV & WFOE & Total \\
\hline Guangzhou & 88 & 21 & 21 & 130 \\
Hainan & 16 & 2 & 9 & 27 \\
Shantou & 36 & 24 & 45 & 105 \\
Shenzhen/Zhuhai & 61 & 15 & 12 & 88 \\
\hline Total & 201 & 62 & 87 & 350 \\
\hline
\end{tabular}

d. Types of Chinese Partners

\begin{tabular}{l|ccc}
\hline Types & EJV & CJV & Total \\
\hline State Owned Enterprise & 123 & 27 & 150 \\
Collectively Owned Enterprise & 23 & 17 & 40 \\
Joint Stock Enterprise & 17 & 4 & 21 \\
Private Enterprise & 10 & 1 & 11 \\
Township-Village Enterprise & 6 & 7 & 13 \\
Information not available & 22 & 6 & 28 \\
\hline Total & 201 & 62 & 263 \\
\hline
\end{tabular}

e. Types of Asset Contribution by Foreign Partners

\begin{tabular}{l|c}
\hline \multicolumn{1}{c|}{ Type } & Frequency \\
\hline Cash + equipment + technology & 98 \\
Cash only & 68 \\
Cash + equipment & 29 \\
Cash + technology & 26 \\
Equipment + technology & 23 \\
Technology only & 53 \\
Equipment only & 22 \\
Information not available & 31 \\
\hline Sum & 350 \\
\hline
\end{tabular}


Table 2. Summaries of Performance Measures

(a) Subjective Performance

\begin{tabular}{cl|ccc}
\hline Category & Performance & Frequency & Percent & Cumulative \\
\hline 1 & poor & 58 & 16.57 & 16.57 \\
2 & satisfactory & 162 & 46.29 & 62.86 \\
3 & good & 49 & 14 & 76.86 \\
4 & excellent & 8 & 2.29 & 79.14 \\
Information not available & & 73 & 20.86 & 100.00 \\
\hline \multicolumn{5}{r|}{} \\
\hline
\end{tabular}

(b) Objective Performance

\begin{tabular}{|c|c|c|c|c|}
\hline Category & Profit & Frequency & y Percent & Cumulative \\
\hline 1 & heavy loss & 32 & 9.14 & 9.14 \\
\hline 2 & minor loss & 107 & 30.57 & 39.71 \\
\hline 3 & $0-3 \%$ & 46 & 13.14 & 52.86 \\
\hline 4 & $3-8 \%$ & 53 & 15.14 & 68 \\
\hline 5 & $8-15 \%$ & 29 & 8.29 & 76.29 \\
\hline 6 & above $15 \%$ & 27 & 7.71 & 84 \\
\hline Information not available & & 56 & 16 & 100 \\
\hline & Total & 350 & 100 & \\
\hline
\end{tabular}


Table 3 a. Definition of the Explanatory Variables

$\mathrm{X}_{1}=$ dummy variable if no cash input is provided by foreign investors;

$\mathrm{X}_{2}=$ dummy variable if no cash and equipment inputs are provided by foreign investors;

$\mathrm{X}_{3}=$ dummy variable if no cash and technology inputs are provided by foreign investor;

$\mathrm{X}_{4}=$ dummy variable if no technology input is provided by foreign investors;

$\mathrm{X}_{5}=$ dummy variable if no equipment input is provided by foreign investors,

$\mathrm{X}_{6}=$ dummy variable if no equipment and technology inputs are provided by foreign investor

(The benchmark case is foreign investors contribute all three kinds of inputs.)

$\mathrm{X}_{7}=$ management input and corporate control variable. It may take the forms of

(1) foreign equity shares,

(2) proportion of board of directors representing foreign investors,

(3) proportion of foreign managers, or

(4) foreign management of the FIEs.

$\mathrm{X}_{8}=\ln$ of duration of operation in years;

$\mathrm{X}_{9}=$ dummy variable if the same foreign parent company owns other FIEs in China;

$\mathrm{X}_{10}=$ export ratio;

$\mathrm{X}_{11}=$ dummy variable, equal to 1 if foreign investor is from Hong Kong, and 0 other wise;

$\mathrm{X}_{12}=$ dummy variable for SEZ;

$\mathrm{X}_{13}$ =agricultural/food products;

$\mathrm{X}_{14}=$ beverages;

$\mathrm{X}_{15}=$ textile;

$\mathrm{X}_{16}=$ leather products;

$\mathrm{X}_{17}=$ paper/wood products;

$\mathrm{X}_{18}=$ chemical products;

$\mathrm{X}_{19}=$ plastic products;

$\mathrm{X}_{20}=$ glass/ceramic ware;

$\mathrm{X}_{21}=$ metal products;

$\mathrm{X}_{22}=$ electric equipment/products;

$\mathrm{X}_{23}=$ electronics products;

$\mathrm{X}_{24}$ = games, toys, jewelry;

$\mathrm{X}_{25}=$ construction/real estates;

$\mathrm{X}_{26}=$ commerce;

$\mathrm{X}_{27}=$ transport services.

(The garment industry serves as a benchmark.) 
Table 3.b. Characteristics of (Non-Dummy) Explanatory

Variables

\begin{tabular}{l|l|ccccc} 
Variable & Unit & Obs. & Mean & Std. Dev. & Min & Max \\
\hline Duration & year & 328 & 3.2 & 2.6 & 0 & 14 \\
Export ratio & percentage & 298 & 50.3 & 38.9 & 0 & 100 \\
Equipment input & percentage & 265 & 60.9 & 44.2 & 0 & 100 \\
Foreign managers & percentage & 288 & 31.8 & 32.5 & 0 & 100 \\
Equity share of foreign parent & percentage & 333 & 69.1 & 26.6 & 10.73 & 100 \\
Total invested capital & \$ million & 320 & 9.4 & 37.3 & 0.018 & 434.08 \\
\hline
\end{tabular}


Table 4. Correlation between Key Variables

a. Subjective and objective performance measures

\begin{tabular}{l|cc}
\multicolumn{2}{c}{$($ obs=251) } & \multicolumn{3}{c}{ subpfm } & profit \\
\hline subpfm & 1.00 & \\
profit & 0.49 & 1.00 \\
\hline
\end{tabular}

b. Foreign equipment and technology inputs and export ratio

\begin{tabular}{l|cccc}
\hline & eqptf & eqptfp & techfp & exptr \\
\hline equipment input & 1.00 & & & \\
eq. from parent & 0.33 & 1.00 & & \\
technology input & 0.21 & 0.43 & 1.00 & \\
export ratio & 0.05 & 0.39 & 0.16 & 1.00 \\
\hline
\end{tabular}

c. Organization and management by foreign parents

\begin{tabular}{l|cccc}
\hline & sharef & mngtf & mngrf & brdpnt \\
\hline equity shares & 1.00 & & & \\
management & 0.29 & 1.00 & & \\
expatriate manager & 0.27 & 0.18 & 1.00 & \\
board of directors & 0.64 & 0.50 & 0.16 & 1.00 \\
\hline
\end{tabular}

d. Duration and multiple ventures

\begin{tabular}{l|cc}
\multicolumn{2}{c}{$($ obs. $=316)$} & \multicolumn{3}{c}{ duration multi-venture } \\
\hline duration & 1.00 & \\
multi-venture & 0.10 & 1.00 \\
\hline
\end{tabular}


Table 5 Regression Results (Profitability as Dependent Variable)

\begin{tabular}{|c|c|c|c|c|c|c|c|c|}
\hline & \multicolumn{2}{|c|}{ model 1} & \multicolumn{2}{|c|}{ model 2} & \multicolumn{2}{|c|}{ model 3} & \multicolumn{2}{|c|}{ model 4} \\
\hline & coef. & $\mathrm{t}$-value & coef. & t-value & coef. & $\mathrm{t}$-value & coef. & t-value \\
\hline \multicolumn{9}{|l|}{ Organization and manage ment } \\
\hline no cash & -0.635 & $-2.192^{* *}$ & -0.467 & $-1.558^{*}$ & -0.526 & $-1.759^{* *}$ & -0.462 & $-1.549^{*}$ \\
\hline no cash and equipment & -0.668 & $-2.481^{* * *}$ & -0.853 & $-1.698^{* *}$ & -0.691 & $-2.395^{* * *}$ & -1.230 & $-2.473^{* * *}$ \\
\hline no cash and technology & -0.465 & $-1.495^{*}$ & -0.237 & -0.749 & -0.280 & -0.903 & -0.272 & -0.892 \\
\hline no technology & -0.356 & $-1.286^{*}$ & -0.262 & -0.945 & -0.217 & -0.803 & -0.108 & -0.397 \\
\hline no equipment & 0.201 & 0.614 & 0.282 & 0.844 & 0.401 & 1.174 & 0.260 & 0.767 \\
\hline no technology \& equipment & -0.207 & -0.798 & -0.159 & -0.633 & 0.019 & 0.083 & 0.016 & 0.063 \\
\hline foreign shares & -0.001 & -0.329 & - & - & - & - & - & - \\
\hline board of directors & - & - & 0.000 & 0.026 & - & - & - & - \\
\hline foreign managers & - & - & - & - & 0.003 & 1.083 & - & - \\
\hline foreign management & - & - & - & - & - & - & 0.284 & $1.448^{*}$ \\
\hline \multicolumn{9}{|l|}{ Transaction costs } \\
\hline Hong Kong & -0.271 & $-1.469^{*}$ & -0.215 & -1.06 & -0.197 & -1.018 & -0.326 & $-1.563^{*}$ \\
\hline Ln (duration of operations) & 0.391 & $3.268^{* * *}$ & 0.482 & $3.832^{* * *}$ & 0.462 & $3.711^{* * *}$ & 0.492 & $3.891^{* * *}$ \\
\hline multiple ventures & 0.094 & 0.554 & 0.137 & 0.74 & 0.177 & 1.003 & 0.076 & 0.404 \\
\hline \multicolumn{9}{|l|}{ Market structure } \\
\hline export ratio & -0.001 & -0.472 & -0.001 & -0.285 & -0.001 & -0.587 & -0.001 & -0.399 \\
\hline garments & - & - & & & & & & \\
\hline agricultural/food products & -0.572 & $-1.76^{* *}$ & -0.439 & -1.204 & -0.530 & $-1.603^{*}$ & -0.376 & -1.003 \\
\hline beverages & -0.100 & -0.208 & -0.016 & -0.031 & -0.114 & -0.236 & 0.113 & 0.231 \\
\hline Textile & 0.061 & 0.153 & 0.222 & 0.514 & -0.094 & -0.209 & 0.218 & 0.506 \\
\hline Leather products & -0.434 & -1.095 & -0.159 & -0.359 & -0.346 & -0.863 & -0.150 & -0.357 \\
\hline paper/wood products & -0.421 & -0.873 & 0.101 & 0.176 & 0.722 & 1.237 & -0.010 & -0.02 \\
\hline chemical products & 0.159 & 0.429 & 0.231 & 0.599 & 0.109 & 0.28 & 0.289 & 0.717 \\
\hline plastic products & 0.096 & 0.286 & 0.030 & 0.081 & 0.000 & 0.001 & 0.084 & 0.234 \\
\hline glass/ceramic ware & -0.187 & -0.445 & -0.263 & -0.483 & -0.219 & -0.472 & -0.458 & -0.756 \\
\hline metal products & -0.490 & $-1.434^{*}$ & -0.299 & -0.819 & -0.417 & -1.172 & -0.239 & -0.663 \\
\hline electric equipment/products & -0.071 & -0.18 & 0.249 & 0.577 & -0.012 & -0.031 & 0.125 & 0.285 \\
\hline electronics products & 0.706 & $2.289^{* *}$ & 0.734 & $2.213^{* *}$ & 0.751 & $2.376^{* * *}$ & 0.735 & $2.233^{* *}$ \\
\hline games, toys, jewelry & -0.255 & -0.654 & 0.348 & 0.734 & 0.360 & 0.777 & 0.466 & 0.993 \\
\hline construction/real estates & -0.643 & -0.956 & -0.501 & -0.714 & 0.201 & 0.187 & -0.657 & -0.811 \\
\hline commerce & 0.106 & 0.272 & 0.353 & 0.825 & 0.088 & 0.212 & 0.272 & 0.615 \\
\hline Transport services & 0.272 & 0.656 & 0.309 & 0.711 & 0.216 & 0.513 & 0.380 & 0.911 \\
\hline \multicolumn{9}{|l|}{ Government policy } \\
\hline special economic zone & -0.363 & $-2.028^{* *}$ & -0.299 & $-1.616^{*}$ & -0.360 & $-1.952^{* *}$ & -0.291 & $-1.568^{*}$ \\
\hline Pseudo $\mathbf{R}^{2}$ & 0.083 & & 0.071 & & 0.090 & & 0.078 & \\
\hline No. of obs. & 221 & & 188 & & 203 & & 188 & \\
\hline
\end{tabular}

Note: $* * *=$ significant at the $1 \%$ level; $* *=$ significant at the $5 \%$ level; $*=$ significant at the $10 \%$ level. 
Table 6. Regression Results (Subjective Performance as Dependent Variable)

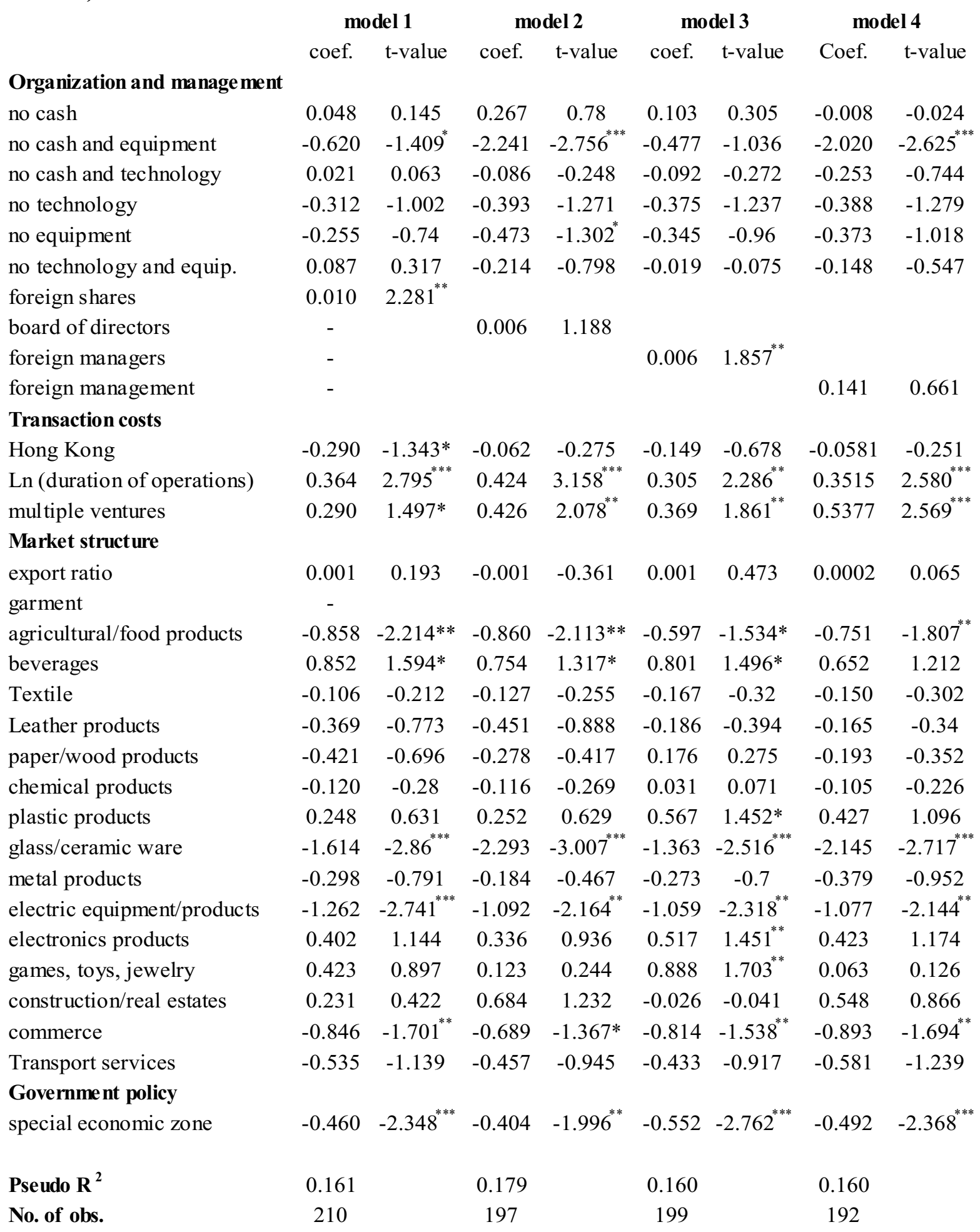

Note: $* * *=$ significant at the $1 \%$ level; $* *=$ significant at the $5 \%$ level; $*=$ significant at the $10 \%$ level. 